\title{
Evaluation of the effects of forest management strategies on carbon sequestration in evergreen broad-leaved (Phoebe bournei) plantation forests using FORECAST ecosystem model
}

Weifeng Wang ${ }^{\mathrm{a}}$, Xiaohua Wei ${ }^{\mathrm{b} *}$, Weiming Liao ${ }^{\mathrm{a}}$, Juan A. Blanco ${ }^{\mathrm{c}}$, Yuanqiu Liu ${ }^{\mathrm{a}}$, Shirong Liu ${ }^{\mathrm{d}}$, Guohua Liu ${ }^{\mathrm{e}}$, Lu Zhang ${ }^{\mathrm{a}}$, Xiaomin Guo ${ }^{\mathrm{a}}$, Shengmao Guo ${ }^{\mathrm{a}}$

a. College of Forestry, Jiangxi Agriculture University, Nanchang, China, 330045

b. Department of Earth and Environmental Sciences, University of British Columbia (Okanagan), 3333 University Way, Kelowna, British Columbia,V1V 1V7, Canada

c. Department of Ciencias del Medio Natural, Universidad Pública de Navarra, Campus de Arrosadia, Pamplona, Navarra, 31013, Spain

d. Institute of Forest Ecology, Environment and Protection, Chinese Academy of Forestry, Beijing, China, 100091

e. State Key Laboratory of Urban and Regional Ecology, Research Center for Eco-Environmental Sciences, Chinese Academy of Sciences, Beijing, China, 100085

* Correspondence to: Xiaohua Wei, Department of Earth and Environmental Sciences, University of British Columbia (Okanagan campus), 3333 University Way, Kelowna, British Columbia, Canada V1V 1V7. Tel.: +1 250807 750; fax: +1 250807 8005; and E-mail addresses: adam.wei@ubc.ca

(C) 2013. This manuscript version is made available under the CC-BY-NC-ND 4.0 license http://creativecommons.org/licenses/by-nc-nd/4.0/ 


\section{Abstract}

In the context of global climate change, it is critical to study how different forest management practices affect forest carbon sequestration. This is especially important for forest managers and policy makers who will have to design and implement appropriate mitigation and adaptation strategies. Previous research has focused on coniferous plantations with rare examination of plantations of evergreen broadleaved species. Phoebe bournei (Hemsley) Yang, as one of the representative species of subtropical evergreen broadleaf forests in Asia, has a unique potential to increase forest carbon sink. In this study, field data were combined with the forest ecosystem management model FORECAST to estimate the impacts of different forest management strategies (combinations of planting densities from 1000 to 4000 trees $\mathrm{ha}^{-1}$, rotation lengths from 20 to 80 years, and different harvesting intensities: stem-only, whole-tree and complete-tree) on carbon sequestration of Phoebe bournei plantations in south-eastern China. Field and previously published data were used to calibrate the model for stand biomass pools accumulation, stand density and mortality, light response curves, photosynthetic efficiency, and data on soil nutrient pools, for three different site conditions. The results showed that the most suitable planting density to maximize carbon sequestration in Phoebe bournei plantations is 2000-3000 trees $\mathrm{ha}^{-1}$. Long rotations (80 years) are better than shorter rotations ( 20 or 30 years) for the long-term maintenance of site productivity, though the recommended rotation length for maximizing carbon sequestration and maintaining forest productivity is 40-60 years. As for harvesting intensity, stem-only harvesting is the most suitable strategy to manage for carbon sequestration when maintaining long-term site productivity, with whole-tree and complete-tree harvesting constituting less optimal options. Our modelling exercise indicates that Phoebe bournei plantations have great potential for carbon sequestration if they are managed under sustainable and ecologically-based strategies. Given that forests are important in the global carbon cycle, it is 
recommended that afforestation efforts in relevant sub-tropical regions use appropriate broad-leaved species that can help resolve ecological and socio-economic challenges.

Keywords: FORECAST ecosystem model; Phoebe bournei plantation; carbon sequestration; sustainable forest management, evergreen broadleaved forests 


\section{Introduction}

Forests account for $40 \%$ of the terrestrial surface and their biomass and primary production contribute $90 \%$ and $70 \%$ to terrestrial ecosystems biomass and productivity, respectively (Korner et al., 2005; Nemani et al., 2003). Forest ecosystems store 1146 Pg C, accounting for about $76 \%$ of all carbon in the terrestrial biosphere, which plays a critical role in regulating regional and global carbon balance (Dxion et al., 1994; IPCC, 2001; Fang et al., 2001).

In China, large-scale deforestation has caused many ecological problems, such as soil erosion, desertification, and biodiversity loss, among others (Wang, 2004). Therefore, reforestation has been suggested as an effective way to restore degraded ecosystems, also helping to mitigate elevated atmospheric $\mathrm{CO}_{2}$, and hence contributing towards the reduction of global warming (Liu and Diamond, 2005). However, most of ecosystems reforested during the past decades in China have been monocultures dominated by coniferous species. However, it has been widely reported that timber yield declines and degradation in soil fertility greatly decreases in coniferous plantations over several rotations (see Bi et al., 2007, and references therein). Transformation of conifer monocultures into mixed conifer-broadleaved or broadleaved plantations has been considered as an efficient strategy to sustain forest productivity and restore degraded forests (Lo et al., 2012). In southern China, evergreen broadleaved forests are the main native ecosystem type in the region, with a potential capacity for carbon sequestration (Wei et al., 2012). Among the native species, Phoebe bournei is one of the most valuable tree species in this subtropical region because of its high-quality wood properties, with significant economic and ecological benefits. According to $\mathrm{Du}$ and $\mathrm{Lu}$ (2009), the volume of 28-year Phoebe bournei plantation can reach 69.14 $76.95 \mathrm{~m}^{3} \mathrm{ha}^{-1}$. P. bournei is mainly distributed in the provinces of Fujian, Hunan, Guizou, Jiangxi and Sichuan (Figure 1). 
Until now, there have been few documented cases of organic matter accumulation and carbon cycle in P. bournei plantations (but see Ma et al., 2009). Given the potential of this species, accurate methods are needed to estimate the capacity of these ecosystems to store and sequester carbon, and the effects that alternative management strategies may have on them. Estimation methods of carbon storage in forests include direct measurements by field research in experimental plots, data checklists to follow a network of permanent plots, and remote sensing estimation. However, all these methods provide only an estimation of ecosystem carbon pools for a given time, without providing dynamical estimates or information on the long-term effects of alternative management or natural disturbances. To solve this problem, dynamic process-based ecological models have been developed that account for the main factors affecting tree and plant growth, assessing the long-term sustainability of management plans (Kimmins et al., 2008).

A large number of forest models have been developed over the last 30 years, and in the latest years the hybrid models combining field date and process simulation are becoming increasingly popular (see Kimmins et al., 2010, and Lo et al., 2011b, for detailed reviews). Among them, the model FORECAST (Kimmins et al., 1999) stands out. It has been used as a management evaluation tool in many types of forest ecosystems around the world (Sachs and Sollins, 1986; Wang et al., 1995; Morris et al., 1997; Wei et al., 2000, 2003; Blanco et al., 2007, Seely et al., 2010), including tropical and sub-tropical forests (Bi et al., 2007; Blanco and González, 2010a b; Xin et al., 2011; Blanco et al., 2012; Wei et al., 2012). The model was specifically designed to examine the impacts of different management strategies or natural disturbance regimes on long-term site productivity and forest carbon sequestration. A detailed description of the FORECAST model can be found in Kimmins et al. (1999, 2010) 
and a brief description of the algorithms simulating $\mathrm{C}$ sequestration will be presented in the next section.

Our initial hypothesis is that Phoebe bournei plantation forests have a large capability for carbon sequestration and storage through wood products, but the ideal combination of tree density, rotation length and harvesting intensity to reach such objective is unclear. Therefore, the objective of our research is to estimate the optimal management prescriptions for Phoebe bournei plantations that maximize carbon sequestration but at the same time are ecologically sustainable in the long-term. To achieve this objective we have combined field research carried out in Phoebe bournei plantations with the simulation of the effects of different forest management strategies using the ecosystem-level forest model FORECAST.

\section{Materials and methods}

\subsection{Study sites and field data collection}

Phoebe bournei is a subtropical tree species of the Laureaceae family, native to the humid mixed subtropical evergreen forests of south-eastern China. It is native of the provinces of Fujian, Hunan, Guizhou, Jiangxi and Sichuan, but it can also be found in Guangdong, Hubei, Zhejiang, and Guangxi (Figure 1). This species has been traditionally used for high-quality furniture and tools, given the high density, colour grain, and pattern that characterize its wood. Traditionally, P. bournei has been grown as single trees or groups in evergreen forests. However, larger trees have become rare in places where there has been more intense exploitation. In addition, the species' preference for fertile lowlands has also brought it into competition with the expansion of agriculture and conifer plantations such as Chinese fir (Cunninghamia lanceolata) (WCMC, 1998). In the recent years, many plantations have been established, either as monoculture or in mixed stands with conifers such as Chinese fir or 
Masson pine (Pinus massoniana). P. bournei is considered a medium/fast growing species, and farmers have generally used a 40-year rotation, with variation from 20 to 50 years depending on site quality. However, the current tendency is towards shorter rotations, a trend driven by the increasing demand for timber due to economic development and population increase.

This study was conducted in research plots established in the subtropical regions of Fujian, Jiangxi and Sichuan provinces. This region has a subtropical monsoon climate with a mean annual temperature of 18.3 and an annual precipitation of $1741 \mathrm{~mm}$. The mean annual frost-free period is 270 days, with average annual sunshine time of 1860 hours. Soils are predominantly red earths and yellow-red soils (lateritic clay-dominated Ferrisoils) with textures ranging from light to medium loam and $\mathrm{pH}$ from 4.7 to 5.2. In this warm and humid subtropical monsoon climate with nutrient-poor soils, $\mathrm{N}$ is usually the growth-limiting factor (Wei et al., 2012; Blanco et al., 2012).

Field research was conducted at Baiyunshan forest farm (Ji'an city), Qiaotou forest farm (Taihe county), and Suichuan county, Jiangxi province (Figure 1). At each site, 9 plots of 20 m x $30 \mathrm{~m}$ were established. Diameter at breast height (DBH at $1.3 \mathrm{~m}$ ) and tree height were measured for every standing tree in the research plots. The Baiyunshan forest farm was established in 1955, with stand density 1667 trees.ha ${ }^{-1}$, being the average DBH of $14.2 \mathrm{~cm}$, tree height of $15.5 \mathrm{~m}$, canopy closure 0.82 , and tree age 21 years. The Qiaotou forest farm was established in 1959, being thinned to stand density of 750 trees $^{-1} a^{-}$. Trees have an average DBH of $32.2 \mathrm{~cm}$, height $21.6 \mathrm{~m}$, and age 47 years. The Suichuan Country plots were located in Changlon village of Dakeng town and Xikou village of Chapanzhou town. Stands ages ranged between 31 to 100 years. Average DBH across plots was $50 \mathrm{~cm}$. 
Five subplots of $5 \mathrm{~m} \times 5 \mathrm{~m}$ were set up within a selected plot. Four subplots were selected in each corner of the main plot and in the centre. In each subplot, aboveground parts of all shrubs and herbs (including ferns and grasses) were cut at the soil surface and weighed separately in the field, and then roots were excavated and weighed after being washed clean. Sub-samples were taken from each understory functional vegetation type (i.e. grasses, herbs, ferns and shrubs) and biomass component (leaves, branches and stems, coarse roots and tubers, fine roots). They were oven-dried in the lab in order to calculate dry biomass, carbon, and $\mathrm{N}$ content on an area basis using the Kjeldhal method (Harwitte, 1980).

Forest floor materials (LFH layer) were sampled by establishing five $1 \mathrm{~m} \times 1 \mathrm{~m}$ subplots within each plot, air-dried, and weighed. Sampling was carried out separately for an upper layer of relatively un-decomposed materials (Llayer), and a lower layer of fragmented or decomposed materials (F and $\mathrm{H}$ layers). Sub-samples were oven dried to constant weight to determine air-to-oven dry biomass ratios. After removing all the organic matter from the forest floor in each subplot, the mineral soil samples were collected using a hand auger (with a diameter of $53 \mathrm{~mm}$ ). All mineral soil samples extended to depth of $60 \mathrm{~cm}$ and were separated into three strata $(0 \sim 20,20 \sim 40$, and 40 60 cm). The samples were used to determine bulk density, and then air-dried and sieved over a $2 \mathrm{~mm}$ mesh for carbon and $\mathrm{N}$ concentration analysis using the Kjeldhal method (Harwitte, 1980).

\subsection{FORECAST model description}

FORECAST is a deterministic, stand-level forest model, which operates at annual time steps. The projection of stand growth and ecosystem dynamics is based on a representation of the rates of key ecological processes regulating the availability of, and competition for, light and 
nutrient resources. The rates of these processes are calculated from a combination of historical bioassay data (biomass accumulation in component pools, stand density, etc.) and measures of certain ecosystem variables (e.g. decomposition rates, photosynthetic saturation curves) by relating biologically active components (foliage and small roots) with calculations of nutrient uptake, capture of light, and net primary production.

An exhaustive description of the input data requirements can be found in Kimmins et al. (1999) (Figure 2). First, calibration data are assembled that describe the accumulation of biomass (above and belowground components) in trees and minor vegetation for chronosequences of stands developed on sites that vary in nutritional quality. Site quality in FORECAST is based on nutritional quality. It is first defined in the calibration files by entering data of tree/plant growth rates and data for ecosystem processes for several sites. Each of these data-site sets is given a number on some user-chosen scale of site quality. In our case, we have used conventional site index (SI) values as a surrogate for site quality $(\mathrm{SI}=$ top tree height at stand age 50 years). The model then uses these definitions and linear interpolations between different site qualities (i.e. SIs) to define changes in the values for these variables in responses to simulated site quality change. These variables include resource allocation, tissue chemistry, internal cycling, litter fall chemistry, decomposition rates, and a number of other site quality-related variables. Later during the simulation, if nutreint availability changes, the model assumes that a change in site quality has occurred, and it changes the values of the variables mentioned earlier accordingly. A detailed description of how site quality is simulated in FORECAST can be found in Kimmins et al. (1999).

Variables in the calibration files are provided as values aggregated at annual time steps (i.e. yearly growth, etc.), and as a consequence the model is insensitive to changes in time scales 
smaller than a year (i.e. seasonal or daily). Tree biomass and stand self-thinning rate data are generated from the height, diameter and stand density from historical growth and yield records in conjunction with species-specific biomass allometric equations. To calibrate the nutritional aspects of the model, data describing the concentration of nutrients in the various biomass components are required. FORECAST also requires data on the degree of shading produced by different quantities of foliage and the response of foliage to different light levels. A comparable but simpler set of data on minor vegetation (understory) must also be provided. Also, data describing the rates of decomposition of various litter types and soil organic matter are required for the model to simulate nutrient cycling. Data are obtained from literature, field measurements, or other empirical models. The second stage of calibration requires establishing the initial site conditions by simulating the known or estimated natural disturbance and/or management history of the site. At this stage, the model is run without accounting for nutrient availability to accumulate vegetation, litter and soil organic matter following the historical patterns of accumulation (for a detailed description of this process see Blanco et al., 2007).

\section{[Figure 2 here]}

The carbon and nitrogen cycles are linked through the use of the foliar nitrogen efficiency (amount of biomass generated in a year per $\mathrm{kg}$ of foliar $\mathrm{N}$ ) as the driving function of the model. Therefore, a limitation in $\mathrm{N}$ uptake will result in a reduction of foliar $\mathrm{N}$, reducing biomass produced by the trees. Nutrient uptake demands on sites of different $\mathrm{N}$ fertility are based on observed biomass accumulation rates and tissue nutrient concentrations on these sites, allowing for internal cycling of nutrients. The calculated uptake demand needed to support the historical growth rates on sites of different productivity permits a definition of nutritional site quality, assuming that moisture is not the major limiting factor in the humid 
climate that characterizes the Phoebe bournei region. Soil fertility in FORECAST (i.e. availability of limiting nutrients, $\mathrm{N}$ in this case) is represented based on empirical input data describing litter and humus decomposition (mass loss) rates, changes in chemistry as decomposition proceeds, and the size of nutrient pools in the mineral soil and humus (cation exchange capacity (CEC) and anion exchange capacity (AEC), respectively). Decomposition rates and ammonium/nitrate ratios in the soil solution are calibrated for each site quality. These parameters implicitly simulate the effects of soil microorganisms on soil organic matter and $\mathrm{N}$ transformations. Nitrogen cycling in FORECAST is based on a mass balance approach where $\mathrm{N}$ can exist in three distinct pools: 1) the plant biomass pool; 2) the available soil nutrient pool, and 3) the soil organic matter/forest floor pool.

However, as in any other modelling exercise, our approach has some limitations, being the main ones the accurate calibration of understory and the representation of soil moisture. The understory vegetation (shrubs and herbs) in Phoebe bournei plantations is usually kept under control by farmers by removing them, and therefore we have simulated only minimum understory biomass levels. However, previous studies have indicated that there can be difference in the ecosystem carbon sequestration of Phoebe bournei plantations due to understory vegetation (Lu, 2006; Peng, 2008a,b; Wei and Ma, 2006). It is not clear which accumulated effects on carbon sequestration that not controlling understory could have, as understory could be both a strong competitor with trees for nutrients and reducing their growth (Bi et al., 2007) or an important carbon pool that could increase ecosystem carbon sequestration (Seely et al., 2010). Unfortunately, there are no records of such practice in current $P$. bournei plantations. In addition, we have used our field data on understory to calibrate the model for the vegetation functional types mentioned earlier, but there are very few detailed ecophysiological data on understory species published. This makes the 
calibration of understory species the most uncertain part of this process. Further detailed field and sensitivity analyses are needed to solve this question.

As for the second issue, the present FORECAST model version does not consider explicitly the impact of moisture, and it does not use climate data directlt for modelling tree growth. Alternatively, it is assumed that site quality, in addition to be mainly determined by nutrient availability, it is also linked to water availability as usually rich, deep soils are found in the valley bottoms or near to water sources (Kimmins et al., 1999). In addition, water limitation is not an important issue in this area with frequent monsoon rains, and the Phoebe bournei plantations studied here grows in subtropical areas with abundant precipitation all the year round (Wei et al., 2012, Blanco et al., 2012). However, if rainfall patterns change in the future due to global warming and water stress increases, tree growth could be reduced and therefore carbon sequestration would also be reduced. In order to explore this issue in more details, the team that has developed the FORECAST model is linking it with the water-limitation model ForWaDy (Kimmins et al., 2010), which will work at daily time steps and use climate data to estimate water limitations. This will make the coupled model sensitive to changes in seasonal climate and it will be more effective in simulating the process of plantation growth, forest hydrology, coupled carbon-water cycles, and carbon sink under water-limited conditions. This would be of great significance in the future research of the local and regional carbon cycles.

\subsection{Model calibration and validation}

FORECAST model calibration required a variety of field and literature data. Data from the research plots used for model calibration were tree height, $\mathrm{DBH}$, tree crown height, branch height, tree aboveground biomass, nutrient concentration, stand density, stand ages, litter 
production dates, soil organic matter content, soil nutrient concentration, and understory vegetation biomass and nutrient concentration, among others. In addition, model calibration also required literature data on Phoebe bournei forests: data of biomass accumulation in component pools and stand density (Chen et al., 1989; Du and Lu., 2009; Jiang et al., 2009; Lu, 1999, 2001; Ma et al., 2008; Peng, 2003, 2008a,b; Son, 2006 ; Wu, 2009; Lu, 2006; Liao et al., 1989); decomposition rates (Cheng, 2003; Guo, 2007; Lin et al., 2006, 2010; Zheng et al., 2011); soil nutrients under different site conditions (Chen, 2010; Liu, 2009; Peng, 2008a,b); and photosynthetic efficiency (Du et al., 2010; Hu and Liu, 2010; Ren et al., 1990; Wu and Chen, 2004), among others. The data to calibrate the model for medium-quality sites (SI $21 \mathrm{~m}$ at age 50 years) and fertile sites $(\mathrm{SI}=25)$ came from field survey and the data for the poor site $(\mathrm{SI}=17)$ from the references cited above.

To assess the performance of FORECAST relative to field observations, data pairs of observed vs. predicted values were subjected to graphical comparisons, assessments of average and absolute biases, and measures of goodness-of-fit (Blanco et al., 2007; Lo et al., 2011a). A linear regression of predicted vs. observed values was fitted to calculate Pearson's correlation coefficient $(r)$. In addition, two different indexes were calculated. The first was Theil's inequality coefficient (Theil, 1966):

$$
U=\sqrt{\frac{\sum_{i=q}^{n} D_{i}}{\sum_{i=1}^{n} \text { Observed }_{i}^{2}}}
$$

where $\mathrm{Di}=$ Observed $\mathrm{i}-$ Predicted $\mathrm{i}$ and $\mathrm{n}$ the number of data pairs. $\mathrm{U}$ can assume values of 0 and greater. If $U=0$ then the model produces perfect predictions. If $U=1$ the model produces predictions of system behaviour that are not better than a no-change prediction. If $U>1$, then the predictive power of the model is worse than the no-change 
prediction. The second index was modelling efficiency (ME), as defined by Vanclay and Skovsgaard (1997) as:

$$
M E=1-\frac{\sum D_{i}^{2}}{\sum\left(\text { Observed }_{i}-\overline{\text { predicted }^{2}}\right)^{2}}
$$

This statistic provides a simple index of performance on a relative scale, where $\mathrm{ME}=1$ indicates a perfect fit, $\mathrm{ME}=0$ reveals that the model is no better than a simple average, while negative values indicate poor model performance. ME is different from the coefficient of determination $r^{2}$ in that ME refers to the difference between observed and simulated data, rather than to the fit of a line minimizing data variability (Vanclay and Skovsgaard, 1997; Blanco et al., 2007). In a second set of analysis, the accuracy of model predictions was determined using the technique described by Freese (1960) as modified by Reynolds (1984). The critical error $e^{*}$, can be interpreted as the smallest error level, in absolute terms, which will lead to accept that the model is within $e$ units of the true value at the given level of confidence. Then, if a user specifies a value of $e$ (difference between real and modeled data) higher than $e^{*}$ then the conclusion will be that the model is adequate. Therefore, these critical errors relate model accuracy to user's requirements. With this test, the model is judged accurate unless there is strong evidence to the contrary. The critical error test was done at $5 \%$ and $20 \%$ error levels $(\alpha=0.05$ and $\alpha=0.20)$, corresponding to an exigent and a less demanding model user, respectively (Reynolds, 1984). Data to evaluate FORECAST performance for Phoebe bournei plantations in the subtropical region of China were obtained from Chen et al. (2007), Cai (2009), Jiang (2009), Liao et al. (1988), Li (2003), Long et al.(2011), Ma (2008), Peng (2003,2008a,b), Sun (2008), Tong (2010), Wei (2006), Wu (2009) and Zhang et al. (2007). These references reported values for plantations in sites described as rich, good, productive or with similar qualitative measures, which were assumed to be equivalent to the simulated rich site. 


\subsection{Management simulations}

After consulting with a panel of forest managers, forest authorities and other stakeholders, the following parameters were identified as the key components of management plans in Phoebe bournei plantation forests. A different set of model runs was carried out to study the influence of each management variables, with values for each parameter set as follows:

- Stand density: 1000, 1500, 2000, 2500, 3000, 3500, and 4000 trees $^{-1}$. Rotation $^{-}$ length was kept constant in 40 years, for six consecutive rotations (total 240 years simulated). Site quality was set to medium $(\mathrm{SI}=21)$ and whole-tree harvesting was used.

- $\quad$ Rotation length: 20, 30, 40, 60, and 80 years. Stand density was kept constant at 2500 tree $\mathrm{ha}^{-1}$, site quality was medium $(\mathrm{SI}=21)$, and whole-tree harvesting was used.

- $\quad$ Harvesting intensity: Stem-only (removing stemwood and stembark), whole-tree (removing all aboveground tree biomass), and complete-tree (removing all aboveground and belowground tree biomass). Stand density was kept constant at 2500 tree ha $^{-1}$, rotation length at 40 years, and site quality was medium (SI=21).

The variables used to assess the effects of forest management on ecosystem carbon were:

- Aboveground Biological Carbon Sequestered (ABCS): carbon sequestered yearly in leaves, branches, stems and bark.

- $\quad$ Underground Biological Carbon Sequestered (UBCS): carbon sequestration in coarse roots (including stump, diameter $>20 \mathrm{~mm}$ ), small roots (diameter 2 20 mm) and fine roots (diameter $<2 \mathrm{~mm}$ ).

- $\quad$ Total Biological Carbon Sequestered (TBCS): TBCS = ABCS + UBCS

- Soil Organic Carbon (SOC): carbon stored in the humus and litter fraction of the soil.

- $\quad$ Total Carbon Sequestered (TCS): TCS = TBCS + SOC 


\section{Results}

\subsection{Model evaluation}

The model acceptably reproduced the main trends for tree height, diameter and total biomass. Although field data had a high dispersion (probably caused by differences in site indexes), FORECAST predictions were close to the average value of field observations and always inside the observed data range (Figure 3). Indexes displayed in Table 1 also indicated an acceptable performance. Pearson's correlation coefficient $(r)$ was high for all variables, with the model being able to reproduce $65 \%$ of observed variance for all variables. Modelling efficiency values showed that FORECAST was an efficient model for the tree variables evaluated, although there was a trend to underestimate diameter at the older ages (Figure 3), which could be caused by field data coming from sites of higher site index than the simulated by FORECAST. Theil's inequality coefficient indicated that predictions by FORECAST were always better than a non-change hypothesis, and the values of Reynolds's critical error $e^{*}$ were similar to the natural variability of observed data for the studied variables, indicating that the model could meet the requirements even of the most exigent user (as defined above).

[Figure 3 here]

[Table 1 here]

\subsection{Effects of planting density on carbon sequestration}

Average annual and rotation values of ABCS, UBCS, TBCS, SOC and TCS were minimum with the lowest stand density (1000 trees $\left.\mathrm{ha}^{-1}\right)$, and increased as planting density increased until reaching a maximum with 3000 trees $\mathrm{ha}^{-1}$, becoming stable with higher densities (Table 2). This effect resulted in a similar trend for accumulated carbon sequestered in different fractions after 240 years (Figure 4). UBCS reaches a plateau after 3000 trees $^{-1}{ }^{-1}$, as the stand 
reached its maximum carrying capacity for root biomass. As a consequence, in high-density stands, changes in TBCS (and thus TCS) are driven mainly by changes in ABCS. The amount of biological carbon fixation was reduced in each rotation when planting density is 1000 trees.ha ${ }^{-1}$. At intermediate densities (i.e. 2000 trees $^{-1}{ }^{-1}$ ) the first 3 rotations (until 120 years) showed a downward trend in soil organic carbon, stabilizing afterwards. When planting density was 2500 trees $\mathrm{ha}^{-1}$, the amount of soil organic carbon per rotation could be maintained stable or slightly increasing. However, the best density for carbon sequestration was 3000 trees $\mathrm{ha}^{-1}$ or above (Table 2, Figure 5). When using different planting density, the proportion of accumulated ABCS in TBCS after 240 years remained relatively stable, ranging from 79.2 to $80.3 \%$ ). However, when going from low to high densities the proportion of TBCS in TCS increased from 50.6 to $54.7 \%$, respectively, making SOC drop from 49.4 to $45.3 \%$.

[Table 2 here]

[Figure 4 here]

[Figure 5 here]

Final SOC after 240 years was lower than at the beginning of the simulation with low planting densities $\left(1000,1500\right.$ or 2000 trees $\left.\mathrm{ha}^{-1}\right)$. When planting density was 2500 trees ha ${ }^{-1}$ or higher, soil organic carbon just decreased slightly. For all planting densities, site quality increased during the first part of the rotation, going from SI 21 to 25 in the middle of the rotation, dropping later again to SI 21 . In addition, there was a long-term trend to reduce the maximum level of SI in each rotation (Figure 5).

\subsection{Effects of rotation length}

Average annual ABCS, UBCS, TBCS, SOC and TCS decreased when rotation length 
increased, whereas the average rotation values for the same variables increased with rotation length (Table 3). Average amount of biological carbon fixation in each rotation was $83.3 \mathrm{Mg}$ $\mathrm{ha}^{-1}$ when rotation length was 80 year, which was 1.39 times of normal rotation (40 years) and 2.75 times that of short rotation (20 years). Total accumulated carbon sequestered after 240 years decreased with increasing rotation length (Figure 6). For 20-year rotations, soil organic carbon was constantly reduced through consecutive rotations until stabilizing after 220 years (Figure 7). When rotation length was 30 years, soil organic carbon also dropped for the first 120 years, stabilizing afterwards. It is necessary to use at least rotation lengths of 40 years (considered as the most frequent rotation in current management plans) to keep carbon sequestration rates stable and sustainable. With longer rotation (60 or 80 years), an increase in soil organic carbon was observed (Figure 7). The proportion of TBCS that was achieved by ABCS after 240 years was only slightly altered by changes in rotation length (79.4 to $81.1 \%$ for short and long rotations, respectively). However, the TBCS/TCS ratio was greatly affected by rotation length, ranging from $40.5 \%$ under short rotations to $59.5 \%$ for long rotations (Figure 8). Site quality during the 240 years simulated showed a fluctuating trend, with site quality increasing from initial SI 21 up to 24 in mid-rotation and dropping afterwards. For a given rotation, site quality increased when nutrients accumulated faster than tree seedlings or mature trees needed to uptake them, but decreased when young trees growing fast did uptake nutrients faster than the soil was able to accumulate. In addition, a general long-term decreasing trend was observed in short rotations, stable in medium rotations and increasing in long rotations (Figure 8).

[Table 3 here]

[Figure 6 here]

[Figure 7 here] 


\subsection{Effects of harvesting intensity}

Average annual and rotation ABCS, UBCS, TBCS, SOC, and TCS values were the highest for stem-only harvesting, with the lowest values being found for complete-tree harvesting, and whole-tree in an intermediate position (Table 4). The same differences among harvesting intensities were found for accumulated carbon sequestered after 240 years, although the differences were relatively small (Figure 8). On the other hand, harvesting the complete tree (removing above- and belowground tree biomass) caused a pronounced long-term decreasing trend in soil organic carbon and site quality after each rotation. A similar trend but less pronounced was found whole-tree harvesting, and it was almost imperceptible for stem-only harvesting, which kept site quality fluctuating in the range SI 21-24 (Figure 9). Harvesting intensity was the less influential parameter on the importance of the aboveground biomass fraction $(\mathrm{ABCS})$ in stand carbon, which only varied from 80.3 to $80.6 \%$ of TBCS. Harvesting intensity affected slightly more the fraction of TCS realized by the vegetation (TBCS), which varied from 53.0 to $54.3 \%$ for stem-only and complete-tree harvesting, respectively.

[Table 4 here]

[Figure 8 here]

[Figure 9 here]

\section{Discussion}

\subsection{Model performance}

When simulating Phoebe bournei plantations, FORECAST seems to perform in an acceptable way for usual forest management standards according to all the indexes of model performance tested in this work. In the present analysis, three different measures of goodness-of-fit were calculated, and in general, all showed acceptable fits between observed and predicted values. Although biases were found for all the three variables, their small 
values were acceptable for regular management plans, which usually deal with degrees of uncertainty higher than the bias produced by the model. The use of a qualitative scale to group the field data for evaluation may have created some of these biases, as stands described as "rich" could in fact had slightly higher or lower site indexes compared to the simulated stands. For example, this could explain the model underestimation of DBH in old stands. Pearson's $r$ coefficient indicated acceptable agreement between observed and predicted values, although $r$ values were lower than $M E$. However, it has been argued that it is not the most reliable measure of model performance (Power, 1993) because the $r$ coefficient is not related to the "perfect fit" line (the line in which observed equals predicted). As a consequence, this coefficient is more about a model's capacity to get a calibration data set to reduce differences between observed and predicted values rather than a measure of the "perfection" of a model's predictions.

Similar insights of model performance were given by Theil's $U$ coefficient. Results for this statistic were always lower than one, indicating that the model is a better predictor than a general mean value. Values of $U, r$ and $M E$ also indicated that the model simulation was efficient and that model outputs produced more accurate scenarios than simple projections of growth and yield tables. $M E$ also pointed out to FORECAST as an efficient model with values close to one. This index has been proposed as an important overall measure-of-fit because $M E$ is a dimensionless statistic that directly relates model predictions to observed data (Mayer and Butler, 1993; Power, 1993; Smith et al. 1997; Vanclay and Skovsgaard, 1997; Blanco et al., 2007). In addition, average biases were also small, in spite of the high dispersion of the field data.

Although goodness-of-fit analysis gives us useful insights into model performance, we also 
should ask whether we could distinguish model predictions from reality (Loehle, 1997; Blanco et al., 2007). Reynolds's critical errors were set as a limit of acceptable accuracy depending on model users' needs. Therefore, FORECAST calibrated for this area would serve well exigent users who specify minimum levels of accuracy above the values presented in Table 1. These values (and more so for a relaxed user) are well inside the levels of uncertainty and error range of most height, diameter and volume assessments carried out in regular management plans. We are confident that the accuracy needs of regular management plans in this area could be met by FORECAST with the data sets used for calibration. This good statistical behaviour is also supported by the graphical results showed in Figure 3, with model predictions inside the range of observed values of the selected variables. All things considered, our results support the use of this ecosystem-level model in the management of Phoebe bournei in this region as a way to improve growth predictions and to develop more adequate forest management plans.

\subsection{Effects of management scenarios on carbon sequestration}

Among the three management parameters studied, the most influential on carbon sequestration was rotation length, followed by plantation density and with harvesting intensity as the less influential. The temporal trends in SOC during the 240 years simulated indicate that there is a significant decline when 20-year and 30-year rotations are used. When rotation length is 40 , SOC remains basically stable. On the other hand, when the rotation is 60 or 80 years, there was a trend to increase SOC. Shorter rotations deplete nutrients and organic matter much more rapidly than do longer rotations. One reason for this is that under short rotations, trees are harvested near the inflexion point of the sigmoideal cumulative growth curve (from fast growth in young trees to slow growth in mature trees). Another reason is that foliar biomass (and the associated crown nutrient capital) stabilizes after crown 
closure (Oliver and Larson, 1996). Thus, under whole-tree harvesting, several short rotations would remove several times more foliage mass than one long rotation because crowns comprise a greater proportion of the biomass in young trees. Switzer et al. (1981) estimated that with whole-tree harvesting, three consecutive 20 -year rotations in an un-thinned loblolly pine forest would remove three-quarters more organic matter, over twice as much $\mathrm{N}$, but only slightly more $\mathrm{C}$ compared to one 60 -year rotation. Another reason for this productivity decline is the reduction of nutrient supplies for trees and the loss of soil organic matter, which is an important reservoir of nutrient for trees, as its mineralization provides a continuous source of nutrients for the soil solution (Kimmins, 2004). The increased stress on soil organic carbon by shorter rotations can also be detected with the low TBCS/TCS ratios (0.405), which indicate that most of the carbon in the ecosystem is in the soil, whereas for the longest rotations the ratio increased by almost 50\% (reaching 0.595 ), and indicating the much more important role of tree biomass in carbon sequestration when longer rotations are used.

The maintenance of carbon sequestration potential, defined as the capacity to generate organic matter through photosynthesis, is paramount to the principles of sustainable forest management. If forestry is to be sustainable, management practices (which in fact are just mere human-induced disturbances), must emulate the effects of natural disturbances on the ecosystem. Since soil organic matter is essential to ecosystem productivity and regeneration, the maintenance of adequate levels of soil organic matter should be an integral component of soil management strategies (Morris et al., 1997, Seely et al., 2010). The concept of ecological rotation, defined as the time required for an element of an ecosystem to recover near its original state following a disturbance event, provides a useful framework for assessing the effects of forest management practices on long-term soil productivity (Kimmins, 1974, Kimmins et al., 2007). However, a decline in ecosystem productivity will likely take place if 
the anticipated economic rotation for a particular site is shorter than the associated ecological rotation. Even though, such decline may be subtle and not easily detected after a single rotation, because of the buffering capacity provided by the nutrient capital stored within the soil organic matter. Evidence of this phenomenon can be found all around the globe from ecosystems subject to long-term harvesting. Observations from plantations in temperate and subtropical sites in the southern U.S.A. (Fox, 2000), New Zealand (Sims et al., 1988), Australia (Johnson, 1992), China (Bi et al., 2007), Spain (Blanco et al., 2005), Cuba (Blanco and González, 2010a,b), and South Africa (Evans, 1996), among others, support this contention but also indicate that the decline in productivity will be cumulative and non-linear across multiple rotations.

The shortest rotation produced the highest amount of sequestered carbon. However, this happens with the decrease of soil organic carbon, which indicates deterioration in site quality that may produce future nutrient limitations for tree growth (Bi et al., 2007). Jiang et al. (2009) found that the capacity of Phoebe bournei plantations for carbon sequestration is stable and maintains site productivity when rotation length is 40 years. This is caused by the Phoebe bournei growth pattern in plantations, which can broadly be divided into three periods: i) Initial growth: 1 to 10 years is the period during which the tree height, diameter at breast height (DBH) and individual timber volume grow slowly; ii) Fast growth: 10 to 20 is the fast growing period, with annual increment in height up to $0.6 \mathrm{~m}$ or more, 10 to 30 years is the time when $\mathrm{DBH}$ increment rises sharply reaching more than $86 \mathrm{~cm}$, timber volume growth gradually accelerate in the 15 to 25 years, and tree height grows at constant speed after 20 years with average annual tree height increments of $0.33 \mathrm{~m}$; and iii) Slow growth: DBH increment slows down after 30 years, and the average annual increment is $0.44 \mathrm{~cm}$, usually reaching maturity around plantation age 35 years. 
From the economic point of view, there is an increasing pressure over Chinese plantation forests to reduce rotation lengths as a way to obtain more frequent revenues and meet the increasing demand for wood products (Blanco et al., 2007; Wei et al., 2012). However, from an ecological point of view, the use of short rotations is not suitable for the accumulation of soil organic carbon in P. bournei plantations. Therefore, if the current trend towards a more ecologically-based plantations is to be sustained (Hammond, 2006), the selection of rotation length should also consider the function of other forest ecosystem services, especially if carbon sequestration is valued through carbon credits or other economic scheme. In addition, using longer rotations may also be a more sustainable business model because it cannot only maintain the ecosystem's capacity to sequester carbon, but also reduce human disturbance and labor and operational costs. However, the economic benefits of extending the rotation could be diminished by discounting interest rates, and it may be possible that little economic gain is achieved unless future price for carbon offsets is higher than current levels. Therefore, it seems that the more reasonable rotation of Phoebe bournei plantations is 40 to 60 years length, which has been the traditional rotation length used by Chinese farmers.

Differences seen among planting densities can be explained by the carrying capacity of the ecosystem (Keith et al., 2010). When planting densities are lower than 2000 trees $^{-1}{ }^{-1}$ there are resources that are not used. Consequently, if more trees are planted, more tree biomass is generated, increasing the plantation capacity to sequester and store carbon. However, there is a threshold around 2500 trees ha ${ }^{-1}$, in which the ecosystem's carbon carrying capacity is reached, and further increases in tree density have no effect. Increasing planting density beyond this threshold would only exacerbate natural thinning in plantation. Therefore, afforestation with high density would not increase the amount of biological carbon 
sequestration effectively, but the losses of trees due to thinning would increase the financial costs, because to keep them alive the ecosystem carrying capacity should be altered by increasing nutrient and water availability through fertilization and irrigation. Therefore, it seems that the suitable plantation density of Phoebe bournei is in the range of 2000-3000 trees $\mathrm{ha}^{-1}$, which is close to the density traditionally used in afforestation practice for this species in China (Li, 2003; Lv, 2006; Liao et al., 1989; Peng, 2008a,b; Sun, 2008; Zhang and $\mathrm{Wu}, 2007)$.

As for harvesting intensity, this parameter seems to have little impact on the total carbon sequestered. However, the removal of root material in complete-tree harvesting also reduces inputs of carbon in the underground portion of the ecosystem, which quickly decreases soil organic matter and its associated nutrients, producing the drop in the site quality. However, after 240 years UBCS reaches the same value regardless of treatments methods, as the reduction in root mass is counterbalanced by the increase in humus produced by the decomposition of aboveground biomass. However, this is not directly translated into a reduction of tree growth and carbon sequestration as these sites have a reservoir of humus that, although being reduced through time, still mineralized enough nutrients to support tree growth. However, if shorter rotations were used or if this type of harvesting were applied on poorer sites, a much quicker drop in site productivity could be expected. Stem-only harvesting also has more advantages than whole-tree or complete-tree harvesting both in the total amount of carbon sequestration and the maintenance of site productivity. This is caused by the lowest removal of nutrients from the site with stem-only harvesting (Blanco et al., 2005), which left most branches, leaves, and root piles in the woodland, which are then decomposed into large amounts of organic matter, increasing available nutrients when it is mineralized afterwards (the "assart effect", Kimmins, 2004). 
In general, it is considered that the evergreen broad-leaved forest ecosystem has strong carbon sequestration capabilities (Waring et al., 1998). Our study has found that the subtropical evergreen broad-leaved Phoebe bournei planted forests also meet this rule. The annual sequestered carbon of Phoebe bournei plantations $\left(1.75-3.73 \mathrm{Mg} \mathrm{ha}^{-1} \mathrm{y}^{-1}\right)$ is higher than that of other Chinese species such as Masson pine, larch, acacia and cork oak $(3.42,1.91$, 0.79 , and $1.03 \mathrm{Mg} \mathrm{ha}^{-1} \mathrm{y}^{-1}$, Ma et al., 2008). It is slightly lower than that of natural spruce forests (2.5 - 5.5 $\mathrm{Mg} \mathrm{ha}^{-1} \mathrm{y}^{-1}$, Jie et al., 2011), and Chinese fir (2.27 - 5.42 $\mathrm{Mg} \mathrm{ha}^{-1} \mathrm{y}^{-1}$, Wei et al., 2012). It is also lower than Michelia macclurei in subtropical zone of Southern Asia (5.78 $\operatorname{Mg~ha}^{-1} \mathrm{y}^{-1}$, Huang et al., 2005).

\subsection{Conclusions}

Our study demonstrates that applying sustainable forest practices in Phoebe plantations can achieve both maximization of carbon sequestration and maintenance of site quality and productivity. Using afforestation densities of 2000-3000 trees $\mathrm{ha}^{-1}$, rotation lengths of 40-60 years, and stem-only harvesting would achieve both carbon sequestration maximization and site productivity maintenance. Therefore, efforts should be done to avoid the temptation of following only short-term economic goals. These could be avoided if ecosystem services such as carbon sequestration and storage are valued and taking into account in management plans. In addition, the Phoebe bournei timber is mostly used to make luxury furniture or building timber, and they will be preserved for a long time, so their carbon storage could be sequestered permanently in relatively stable carbon pools, a fact that is of great significance in regulating the turnover rate and turnover volume of carbon in the atmosphere.

The anticipated trend for future climate in the region is to temperature increase of $1-1.5^{\circ} \mathrm{C}$ by 
2050 and potential increases in precipitation (Wu et al 2004). This trend has already been detected in the historic climate of the region during the last past 40 years, which have seen an increase of $2{ }^{\circ} \mathrm{C}$ and $20 \%$ in precipitation between 1960 and 2000 (Zhang et al. 2010). If the observed changed in the historical climate records continues in the future as expected, it will likely produce a slight increase in NPP in the forests in the region. This trend could also be reinforced by the expected increase in $\mathrm{N}$ deposition from atmospheric pollution (Wei et al. 2012). All together, it could mean that forest plantations in SE China would become more productive. This could be translated into reductions in rotation length or increases in harvesting intensity (i.e. whole tree versus stems-only). Alternatively, reducing tree density could become a more attractive option as it may be possible to get faster bigger trees (and therefore more valuable forest products). However, if a reduction in rotation length or plantation density, and more complete use of harvesting products could be acceptable under more favourable climatic conditions, things could be different if $\mathrm{N}$ deposition is also taken into account. Shorter and more intense rotations would also keep stands open without tree cover during longer time, which would be translated into less $\mathrm{N}$ use and therefore increases $\mathrm{N}$ leaching losses (Wei et al. 2012). In addition, the frequency and intensity of stand-replacing disturbances (i.e. typhoons) may also change. If they become more intense, harvesting plantations more often (i.e. shorter rotations) could be a strategy to reduce losses. This discussion has been included in the conclusions section.

Our research has also shown the feasibility of using ecosystem-level process-based modelling combined with field research on permanent plots as a method to estimate carbon sequestration and to study the effects of alternative management strategies on plantations forests. 


\section{Acknowledgements}

This study has received the support from the special grant of the Forestry Public Research and Development (201104006), which is part of the Chinese Academy of Sciences Strategic Project (XDA05060101). The study has also been supported by the Jiangxi Provincial Science and Technology International Cooperation Project (09003614) and The Ministry of Education of Jiangxi Province through the Provincial Agriculture Science and Technology Program (2010BSA19400). To all of them we express our gratitude.

\section{References}

Bi, J., Blanco J.A., Kimmins J.P., Ding Y., Seely B., Welham C. 2007. Yield decline in Chinese Fir plantations: A simulation investigation with implications for model complexity. Canadian Journal of Forest Research 37, 1615-1630.

Blanco, J.A., González E. 2010a. The legacy of forest management in tropical forests: analysis of its long-term influence with ecosystem-level model. Forest Systems 19(2), 249-262.

Blanco, J.A., González E. 2010b. Exploring the sustainability of current management prescriptions for Pinus caribaea plantations in Cuba: a modelling approach. Journal of Tropical Forest Science 22(2), 139-154.

Blanco, J.A., Seely B., Welham C., Kimmins J.P., Seebacher T.M. 2007. Testing the performance of FORECAST, a forest ecosystem model, against 29 years of field data in a Pseudotsuga menziesii plantation. Canadian Journal of Forest Research 37, 1808-1820.

Blanco, J. A., Zavala, M. A., Imbert, J. B., Castillo, F. J. 2005. Evaluation of thinning sustainability using a nutrient cycling simulation model. Forest Ecology and Management 213, 209-228.

Cai, S. 2009. Carbon storage and allocation in 26 years old Phobe bournei and Cunninghamia lanceolata plantations. Journal of Fujian Forestry Science and Technology 36(4), 9-25 (in Chinese, with English abstract).

Chen, C. 2005. Study on cultivate characteristic and management result of Phoebe bournei. Thesis, Fujian Agriculture and Forestry University, Fujian, PR China (in Chinese, with English abstract).

Chen, C., Liu B., Li S., et al. 2007. Management effect of artificial forest of Phoebe bournie in Fujian. Journal of Fujian College of Forestry 27 (2), 101-104 (in Chinese, with English abstract).

Chen, S. 2010. Effect of different site conditions on the growth of Phoebe bournei. Journal of Fujian College of Forestry 30(2), 157-160 (in Chinese, with English abstract). 
Cheng, Y. 2003. Study on litter fall Decomposing dynamic and nutrients releasing rule of Phoebe bournei. Thesis, Fujian Agriculture and Forestry University, Fujian, PR China (in Chinese, with English abstract).

Dixon, R.K, Brown S, Houghton A.M , Trexier M.C., Wisniewski, J. 1994. Carbon pools and flux of global forest ecosystem. Science 263, 185-190.

Du, J., Lu. 2009. Study on growth regularity of Phoebe zhennan plantation. Journal of Zhejiang Forestry Science and Technology 29(5), 9-12 (in Chinese, with English abstract).

Du, J., Lu. 2009. Study actuality and expectation on Phoebe zhennan Plantation. Journal of Anhui Agriculture and Science 37(33), 16610-16612 (in Chinese, with English abstract).

Du, J., Fan Z.,Ye D., et al. 2010. The predicting models of crown volume and LAI for Phoebe zhennan plantation. Journal of Zhejiang Forestry Science and Technology 30(4),37-41 (in Chinese, with English abstract).

Evans, J. 1996. The sustainability of wood production from plantations: evidence over three successive rotations in the Usutu Forest, Swaziland. Commonwealth Forestry Reviews 75, 234-239.

Fang, J.Y, Chen A.P, Peng C.H, Zhao S.Q., Ci L.J. 2001. Changes in forest biomass carbon storage in China between 1949 and 1998. Science 292, 2320-2322.

Fox, T. R. 2000. Sustained productivity in intensively managed plantations. Forest Ecology and Management 138, 187-202.

Freese, F. 1960. Testing accuracy. Forest Science 6, 139-145.

Guo Y. 2007. Decomposition and the nutrient dynamics of Phoebe bournei leaf litter. Journal of Fujian College of Forestry 27(3), 199-202 (in Chinese, with English abstract).

Harwitte, W. 1980. Official methods of analysis of the Association of Official Analytical Chemists. 13th edition. Association of Official Analytical Chemists, Washington, D.C., USA.

Hu, J., Liu G. 2010. Preliminary investigation on photosynthetic characteristics of saplings of Phoebe zhennan and Machilus leptophylla. Journal of Anhui Agricultural University 37(3), 541-546 (in Chinese, with English abstract).

Huang, Y., Feng Z.W, Wang S.L, et al. 2005. C and N stocks under three plantation forest ecosystems of Chinese-fir, Michelia macclurei and their mixture. Acta Ecologica Sinica 25(12), 3146-3154 (in Chinese, with English abstract).

IPCC Climate change. 2007: The physical scientific basis. The fourth assessment report of working group. Cambridge: Cambridge University Press.

Jiang, X., Xiao F., Ye J., et al. 2009. A study on the growth characteristics of Phoebe bournei in natural forest and plantation stands.Acta Agriculturae Universitatis Jiangxiensis 31(6),1049-1054 (in Chinese, with English abstract). 
Jie, C., Jiang H., Zhou G., Wei X., Blanco J.A., Jiang Z., Xin Z. 2011. Simulating the carbon storage of spruce forests based on the FORECAST model and remotely sensed data. Proceedings - 2011 19th International Conference on Geoinformatics, Geoinformatics 2011. Article number 5981581.

Johnson, D.W. 1992. Effects of forest management on soil carbon storage. Water, Air and Soil Pollution 64, 83-120.

Keith, H., MaKey, B., Berry, S., Lindenmayer, D., Gibbons, P. 2010. Estimating carbon carrying capacity in natural forest ecosystems across heterogeneous landscapes: addressing sources of error. Global Change biology 16, 2971-2989.

Kimmins, J. P. 1974. Sustained yield, timber mining, and the concept of ecological rotation: a British Columbian view. The Forestry Chronicle 50, 27-31.

Kimmins, J. P. 2004. Forest Ecology: a foundation for sustainable forest management and environmental ethics in forestry (3rd Ed.). Upper Saddle River, NJ: Prentice Hall.

Kimmins, J.P., Mailly D, Seely B. 1999. Modelling forest ecosystem net primary production: the hybrid simulation approach used in FORECAST. Ecological Modelling 122, 195-224.

Kimmins, J.P. Blanco J.A., Seely B., Welham C., Scoullar K. 2008. Complexity in Modeling Forest Ecosystems; How Much is Enough? Forest Ecology and Management 256, 1646-1658.

Kimmins J.P., Blanco J.A., Seely B., Welham C., Scoullar K. 2010. Forecasting Forest Futures: A Hybrid Modelling Approach to the Assessment of Sustainability of Forest Ecosystems and their Values. Earthscan Ltd. London, UK. 281 pp. ISBN: 978-1-84407-922-3.

Kimmins, J. P., Welham, C., Seely, B., Van Rees, K. 2007. Biophysical sustainability, process-based monitoring and forest ecosystem management decision support systems. The Forestry Chronicle $83,502-514$.

Korner, C., Asshoff R., Bignucolo O., Hättenschwiler S., Keel S.G., Perláez-Riedl S., Pepin S., Siegwolf R.T.W., Zotz G. 2005. Carbon flux and growth in mature deciduous forest trees exposed to elevated $\mathrm{CO}_{2}$. Science 309, 1360-1362.

Li, S. 2003. Comprehensive evaluations of various afforestation patterns Phoebe bournei. Acta Agriculturae Universitatis Jiangxiensis 25(5), 100-103 (in Chinese, with English abstract).

Liao, H., Zhang C., Chen D. 1988. Biomass of the cultivated Phoebe bournei stands. Journal of Fujian College of Forestry 8(3), 252-257 (in Chinese, with English abstract).

Liao, H., Di D., Zhang C., et al. 1989. Planting density management to Cinnamoum camphora and Phoebe bournei.Journal of Fujian College of Forestry 9(4), 80-84 (in Chinese, with English abstract).

Liao, L. 1997. The growth rhythm of Machilus pauhoi Kanehira . Journal of Jiangsu Forestry Science and Technology 24(1), 39-41 (in Chinese, with English abstract). 
Lin K., Zhang Z., Cao G., et al. 2006. Decomposition characteristics and its nutrient dynamics of leaf litter mixtures of both Chinese fir and Phoebe bournei. Acta Ecologica Sinica 26(8), 2732-2738 (in Chinese, with English abstract).

Lin, K., Zhang Z., Ye F., et al. 2010. Dynamic analysis of decomposition characteristics and content change of nutrient elements of leaf litter of Cunninghamia lanceolata, Phoebe bournei and Schima superba under C. lanceolata artificial forest. Journal of Plant Resources and Environment 19(2), 34-39 (in Chinese, with English abstract).

Lin, Y. 2007. Study on the productivity of Phoebe bournei accompanied by Cunninghamia lanceolata. Journal of Fujian Forestry Science and Technology 34(4),38-41(in Chinese, with English abstract).

Liu, Q. 2009. Study of soil fertility of Phoebe bournei planted forest. Journal of Jiangxi Forestry Science and Technology 1, 31-33 (in Chinese, with English abstract).

Liu, J., Diamond J. 2005. China's environment in a globalizing world. Nature 435, 1179-1186.

Lo, Y.-H., Blanco J.A., Seely B., Welham C., Kimmins J.P. 2011a. Generating reliable meteorological data in mountainous areas with scarce presence of weather records: the performance of MTCLIM in interior British Columbia, Canada. Environmental Modelling and Software 26, 644-657.

Lo Y.-H., Blanco J.A., Kimmins, J.P., Seely B., Welham C. 2011b. Linking climate change and forest ecophysiology to project future trends in tree growth: a review of forest models. In Blanco J.A., Kheradmand H. (Eds.) 2011. Climate Change - Research and Technology for adaptation and mitigation. InTech, Rijeka, Croatia. Pp 63-86. ISBN: 979-953-307-278-3.

Lo Y.-H., Lin Y.-C., Blanco J.A., Yu C.-H., Guan B.T. 2012. Moving from ecological conservation to restoration: an example from central Taiwan, Asia. In Blanco J.A., Lo, Y.-H. (Eds.) Forest Ecosystems: more than just trees. Pp 339-354. InTech, Rijeka, Croatia. ISBN: 978-953-307-667-6.

Lohele, C. 1997. A hypothesis testing framework for evaluating ecosystem model performance. Ecological Modelling 97, 153-165.

Long, H., Zhang W., Song P., et al. 2011. An analysis of the growth of Phoebe zhennan in Sichuan. Journal of Sichuan Forestry Science and Technology 32(4), 89-91 (in Chinese, with English abstract).

Lu, M. 2006. Study on biomass and nutrient of Phoebe bournei plantation in heterogeneity spatiality of density and site. Fujian Agriculture and Forestry University, Fujian, PR China (in Chinese, with English abstract).

Ma, M., Jiang H., Liu Y. 2008. Biomass, carbon content, carbon storage and their vertical distribution of Phoebe bournei artificial stand . Scientia Silvae Sinicae 44(3), 34-39 (in Chinese, with English abstract).

Mayer, D.G., Butler, D.G. 1993. Statistical validation. Ecological Modelling 68, 21-32. 
Mi N., Yu G., Wen X., Sun X., Wang S. 2008. Responses of subtropical conifer plantation to future climate change: A simulation study. Chinese Journal of Applied Ecology 19(9), 1877-1883 (in Chinese, with English abstract).

Morris, D.M, Kimmins J.P, Duckert D.R. 1997. The use of soil organic matter as a criterion of the sustainability of forest management alternatives: a modeling approach using FORECAST. Forest Ecology and Management 94, 61-78.

Nemani, R.R., Keeling C.D., Hashimoto H., Jolly W.M., Piper S.C., Tucker C.J., Myneni R.B., Running S.W. 2003. Climate driven increases in global terrestrial net primary production from 1982 to 1999. Science 300,1560-1563.

Oliver, C.D., Larson, B.C. 1996. Forest stand dynamics (Update Ed.) New York, NY: Wiley and Sons. Peng, L. 2003. Biomass and productivity in 35a old Phoebe bournei plantation. Journal of Fujian College of Forestry 23 (2), 128-131 (in Chinese, with English abstract).

Peng, L. 2008a. Preliminary study on the biomass of Phoebe bournei plantation with different density and site condition. Journal of Fujian Forestry Science and Technology 35(4),15-23 (in Chinese, with English abstract).

Peng, L. 2008b. Study on nutrient elements of Phoebe bournei plantation in the different site conditions. Journal of Fujian Forestry Science and Technology 35(2), 10-15 (in Chinese, with English abstract).

Power, M. 1993. The predictive validation of ecological and environment models. Ecological Modelling 68, 33-50.

Ren, C., Chen H., Zhou L. et al. 1990. Study on L.A.I.(Leaf Area Index) of Phoebe bournei stand in Youxi county. Journal of Fujian College of Forestry 10(1), 67-71 (in Chinese, with English abstract)

Reynolds, M.R. 1984. Estimating the error in model predictions. Forest Sciences 30, 454-469.

Sachs, D., Sollins P. 1986. Potential effects of management practices on nitrogen nutrition and long-term productivity of western Hemlock Stands. Forest Ecology and Management 17, 25-36.

Seely, B., Welham C, Kimmins H. 2002. Carbon sequestration in a boreal forest ecosystem: results from the ecosystem simulation model, FORECAST. Forest Ecology and Management 169, 123-135.

Seely, B., Hawkins C., Blanco J.A, Welham C., Kimmins J.P. 2008. Evaluation of a mechanistic approach to mixedwood modelling . The Forestry Chronicle 84(2), 181-193.

Seely, B., Welham C., Blanco J.A. 2010. Towards the application of soil organic matter as an indicator of ecosystem productivity: Deriving thresholds, developing monitoring systems, and evaluating practices. Ecological Indicators 10, 999-1008.

Sims, A., Oliver, G.R., Dyck W.J. 1988. Effects of forest management on the long-term productivity of Nelson soils - Estimate of nutrient removal. Proj. Rec. No.2034. Rotorua, New Zealand: Forest Research.Institute. 
Smith, E.P., Rose K.A. 1995. Model goodness-of-fit analysis using regression and related techniques. Ecological Modelling 77, 59-64.

Sun, X. 2008. Study on the effect of thinning on the growth of mixed forest of Phoebe bournei and Cunninghamia lanceolata. Subtropical Agriculture Research 4(3),184-187 (in Chinese, with English abstract).

Switzer, G.L., Nelson, L.E., Hinesley, L.E. 1981. Effects of utilization on nutrient regimes and site productivity. In: S.P. Gessel, R.M. Kenady, W.A. Atkinson (Eds.), Proceedings Forest Fertilization conference, Union WA, 25-27 Sept. 1979. Inst forest Resources contribution No 40 (pp. 251-259). Seattle, WA: College of forest resources, University of Washington.

Theil, H. 1966. Applied econometric forecasting. North-Holland, Amsterdam, 474 pp.

Tong, G. 2010. Study on the effect of aspect and afforestation density on Machilus Paunoi Kanenira young forest growth. Jour of Fujian Forestry Science and Technology 37(4), 70-72 (in Chinese, with English abstract).

Vanclay, J.K. Skovsgaard, J.P. 1997. Evaluating forest growth models. Ecological Modelling 98, 1-12. Wang, P. 2009. Forest carbon cycle model : A review. Journal of Applied Ecology 20 (6),1505-1510 (in Chinese, with English abstract).

Wang, Y. 2004. Environmental degradation and environmental threats in China. Environmental Monitoring and Assessment 90, 161-169.

Wang, J.R., Comeau P., Kimmins J.P. 1995. Simulation of mixedwood management of aspen and white spruce in Northeastern British Columbia. Water, Air and Soil Pollution 82, 171-178.

Waring, R., Running S. 1998. Forest ecosystems, analysis at multiple scales. New york: Academic Press.

Wei, H., Ma X. 2006. Study on the carbon storage and distribution of Phoebe bournei plantation ecosystem of different growing stages. Yantai Normal University Journal 22(2),130-133 (in Chinese, with English abstract).

Wei, X., Blanco J.A., Jiang H., Kimmins J.P. 2012. Effects of nitrogen deposition on carbon sequestration in Chinese fir forests. Science of Total Environment 416, 351-361.

Wei, X., Liu W., Waterhouse M., Armleder M. 2000. Simulation on impacts of different management strategies on long-term site productivity in lodgepole pine forests of the central interior of British Columbia. Forest Ecology and Management 133, 217-229.

Wei, X., Kimmins J.P., Zhou G. 2003. Disturbance and the sustainability of long-term site productivity in lodgepole pine forests in the central interior of British Columbia - an ecosystem modeling approach . Ecological Modelling 164, 239-256. 
Welham, C., Seely B., Kimmins J.P. 2002. The utility of the two-pass harvesting system: an analysis using the ecosystem simulation model FORECAST. Canadian Journal of Forest Research 32, 1071-1079.

World Conservation Monitoring Centre. 1998. Phoebe bournei. In: IUCN 2011. IUCN Red List of Threatened Species. Version 2011.2. <www.iucnredlist.org>. Downloaded on 24 March 2012. Wu, Z. 2005. Study on growth effect of the mixed forest of Cunninghamia lanceolata and Phoebe bournei. Journal of Fujian College of Forestry 25(2), 142-146(in Chinese, with English abstract).

Wu, W. 2009. Study on stand structure and growth law of near mature Phoebe bournei plantation. Development of Forestry Science and Technology 23(5),75-78 (in Chinese, with English abstract).

Wu, X. 2005. Research on introduction and cultivation of Phoebe bournei. Jiangxi forestry Science and Technology 5, 11-12 (in Chinese, with English abstract).

Wu, Z., Chen S. 2004. The effect of light on growth of Phoebe bournei plantation. Journal of Fujian College of Forestry 24(4), 371-373 (in Chinese, with English abstract).

Wu J., Tong C., Liu S. 2004. Responses of soil organic carbon to global climate changes in cultivated soils in the subtropical and the loess plateau regions. Advance in Earth Sciences 19(1), 131-137 (in Chinese, with English abstract).

Xie, G. 2011. Diameter at breast height estimation models based on multiple growth indices of Phoebe zhennan. Forestry Science and Technology 36(2), 41-44 (in Chinese, with English abstract).

Xin, Z.-H., Jiang H., Jie C.-Y., Wei X., Blanco J.A., Zhou G.M. 2011. Simulated nitrogen dynamics for a Cunninghamia lanceolata plantation with selected rotation ages. Journal of Zhejiang Forestry College 28(6), 855-862 (in Chinese, with English abstract).

Zhang, W., Wu Z. 2007. Experiment study on different nurturing measures of Phoebe bournei plantation. Journal of Minxi Vocational and Technical College 9(2), 1-4 (in Chinese, with English abstract).

Zhang J., Qian H., Lai C. 2010. Temperature suitability and its change trend of Cinnamomum camphora in subtropical China. Chinese Journal of Ecology 29(8), 1482-1487 (in Chinese, with English abstract).

Zheng, J., Liu X., Gao R., et al. 2009. Carbon storage and allocation in the Phoebe bournei plantations in Nanping, Fujian province. Journal of Subtropical Resources and Environment 4(4), 59-65 (in Chinese, with English abstract).

Zheng, J., Yang Z., Ling H., et al. 2011. Litterfall production and its monthly dynamics of Phoebe bournei plantation. Journal of Fujian Normal University 27(1), 88-92 (in Chinese, with English abstract). 


\section{Tables}

Table 1. Indexes of FORECAST performance for simulations of Phoebe brunei plantations established on sites of medium quality $(\mathrm{SI}=21)$ in south-eastern China (see main text for references for field data). $e^{*}$ : value of Reynolds (1984) critical error at two different levels of confidence $(95 \%$ and $80 \%)$.

\begin{tabular}{lccc}
\hline \multicolumn{1}{c}{ Index } & Top height & Dominant DBH & Total tree biomass \\
\hline Average bias & $-0.55 \mathrm{~m}$ & $-0.31 \mathrm{~cm}$ & $1.40 \mathrm{Mg} \mathrm{ha}^{-1}$ \\
Mean absolute deviation & $2.71 \mathrm{~m}$ & $3.26 \mathrm{~cm}$ & $24.75 \mathrm{Mg} \mathrm{ha}^{-1}$ \\
Pearson's $r$ & 0.81 & 0.80 & 0.80 \\
Modelling efficiency & 0.96 & 0.95 & 0.94 \\
Theil's coefficient & 0.22 & 0.24 & 0.21 \\
Relaxed $e^{*}(\alpha=0.05)$ & $5.52 \mathrm{~m}$ & $6.91 \mathrm{~cm}$ & $45.40 \mathrm{Mg} \mathrm{ha}^{-1}$ \\
Exigent $e^{*}(\alpha=0.20)$ & $3.96 \mathrm{~m}$ & $4.94 \mathrm{~cm}$ & $33.34 \mathrm{Mg} \mathrm{ha}^{-1}$ \\
\hline
\end{tabular}


Table 2. Effects of different plantation densities on carbon-related variables (see text for variable definitions).

\begin{tabular}{|c|c|c|c|c|c|c|c|c|c|c|}
\hline \multirow{2}{*}{$\begin{array}{l}\text { Density } \\
\left(\text { trees ha }{ }^{-1}\right)\end{array}$} & \multicolumn{5}{|c|}{ Annual average $\left(\mathrm{Mg} \mathrm{ha}^{-1} \mathrm{yr}^{-1}\right)$} & \multicolumn{5}{|c|}{ Rotation average $\left(\mathrm{Mg} \mathrm{ha}^{-1}\right.$ rotation $\left.^{-1}\right)$} \\
\hline & $\mathrm{ABCS}$ & UBCS & TBCS & SOC & TCS & ABCS & UBCS & TBCS & SOC & TCS \\
\hline 1000 & 0.94 & 0.25 & 1.19 & 1.16 & 2.35 & 37.72 & 9.90 & 47.62 & 46.58 & 94.19 \\
\hline 1500 & 1.04 & 0.26 & 1.30 & 1.21 & 2.51 & 41.41 & 10.56 & 51.97 & 48.32 & 100.30 \\
\hline 2000 & 1.13 & 0.29 & 1.42 & 1.24 & 2.66 & 45.33 & 11.58 & 56.91 & 49.39 & 106.30 \\
\hline 2500 & 1.20 & 0.29 & 1.50 & 1.26 & 2.76 & 48.16 & 11.80 & 59.96 & 50.33 & 110.28 \\
\hline 3000 & 1.22 & 0.30 & 1.52 & 1.28 & 2.80 & 48.93 & 11.98 & 60.91 & 51.12 & 112.03 \\
\hline 3500 & 1.22 & 0.30 & 1.52 & 1.28 & 2.80 & 48.93 & 11.98 & 60.91 & 51.12 & 112.03 \\
\hline 4000 & 1.22 & 0.30 & 1.52 & 1.28 & 2.80 & 48.93 & 11.98 & 60.91 & 51.12 & 112.03 \\
\hline
\end{tabular}


Table 3. Effects of different rotation lengths on carbon-related variables (see text for variable definitions).

\begin{tabular}{|c|c|c|c|c|c|c|c|c|c|c|}
\hline \multirow{2}{*}{$\begin{array}{l}\text { Rotation } \\
\text { (years) }\end{array}$} & \multicolumn{5}{|c|}{ Annual average $\left(\mathrm{Mg} \mathrm{ha}^{-1} \mathrm{yr}^{-1}\right)$} & \multicolumn{5}{|c|}{ Rotation average $\left(\mathrm{Mg} \mathrm{ha}^{-1}\right.$ rotation $\left.^{-1}\right)$} \\
\hline & ABCS & UBCS & TBCS & SOC & TCS & $\mathrm{ABCS}$ & UBCS & TBCS & SOC & TCS \\
\hline 20 & 1.21 & 0.30 & 1.51 & 2.22 & 3.73 & 24.20 & 6.06 & 30.27 & 44.39 & 74.66 \\
\hline 30 & 1.22 & 0.30 & 1.52 & 1.59 & 3.11 & 36.52 & 9.06 & 45.58 & 47.69 & 93.27 \\
\hline 40 & 1.20 & 0.29 & 1.50 & 1.26 & 2.76 & 48.16 & 11.80 & 59.96 & 50.33 & 110.28 \\
\hline 60 & 1.03 & 0.24 & 1.27 & 0.91 & 2.17 & 61.63 & 14.41 & 76.04 & 54.33 & 130.37 \\
\hline 80 & 0.83 & 0.21 & 1.04 & 0.71 & 1.75 & 66.16 & 17.15 & 83.31 & 56.67 & 139.98 \\
\hline
\end{tabular}


Table 4. Effects of different harvesting intensities (SO: Stem-only; WT: whole-tree; CT: complete-tree harvesting) on carbon-related variables (see text for variable definitions).

\begin{tabular}{|c|c|c|c|c|c|c|c|c|c|c|}
\hline \multirow{2}{*}{$\begin{array}{c}\text { Harvesting } \\
\text { method }\end{array}$} & \multicolumn{5}{|c|}{ Annual average $\left(\mathrm{Mg} \mathrm{ha}^{-1} \mathrm{yr}^{-1}\right)$} & \multicolumn{5}{|c|}{ Rotation average $\left(\mathrm{Mg} \mathrm{ha}^{-1}\right.$ rotation $\left.^{-1}\right)$} \\
\hline & ABCS & UBCS & TBCS & SOC & TCS & $\mathrm{ABCS}$ & UBCS & TBCS & SOC & TCS \\
\hline SO & 1.20 & 0.29 & 1.49 & 1.25 & 2.74 & 47.81 & 11.71 & 59.52 & 50.14 & 109.66 \\
\hline WT & 1.17 & 0.29 & 1.45 & 1.25 & 2.70 & 46.66 & 11.41 & 58.07 & 49.81 & 107.88 \\
\hline CT & 1.11 & 0.27 & 1.38 & 1.23 & 2.61 & 44.45 & 10.86 & 55.32 & 49.13 & 104.44 \\
\hline
\end{tabular}




\section{Figure legends}

Figure 1. Main area of distribution of Phoebe bournei in China and location of the research plots.

Figure 2. A schematic representation of the ecosystem compartments and transfer pathways represented in FORECAST (adapted from Kimmins et al., 1999).

Figure 3. Comparison between observed and simulated values for three stand variables.

Figure 4. Effects of different plantation densities on carbon-related variables after 240 years.

Figure 5. Temporal changes in soil organic carbon and site quality under different plantation densities during 240 years of simulation.

Figure 6. Effects of different rotation lengths on carbon-related variables after 240 years.

Figure 7. Temporal changes in soil organic carbon and site quality under different rotation lengths during 240 years of simulation.

Figure 8. Effects of different harvesting methods on carbon-related variables after 240 years.

Figure 9. Temporal changes in soil organic carbon and site quality under different harvesting intensities during 240 years of simulation. 


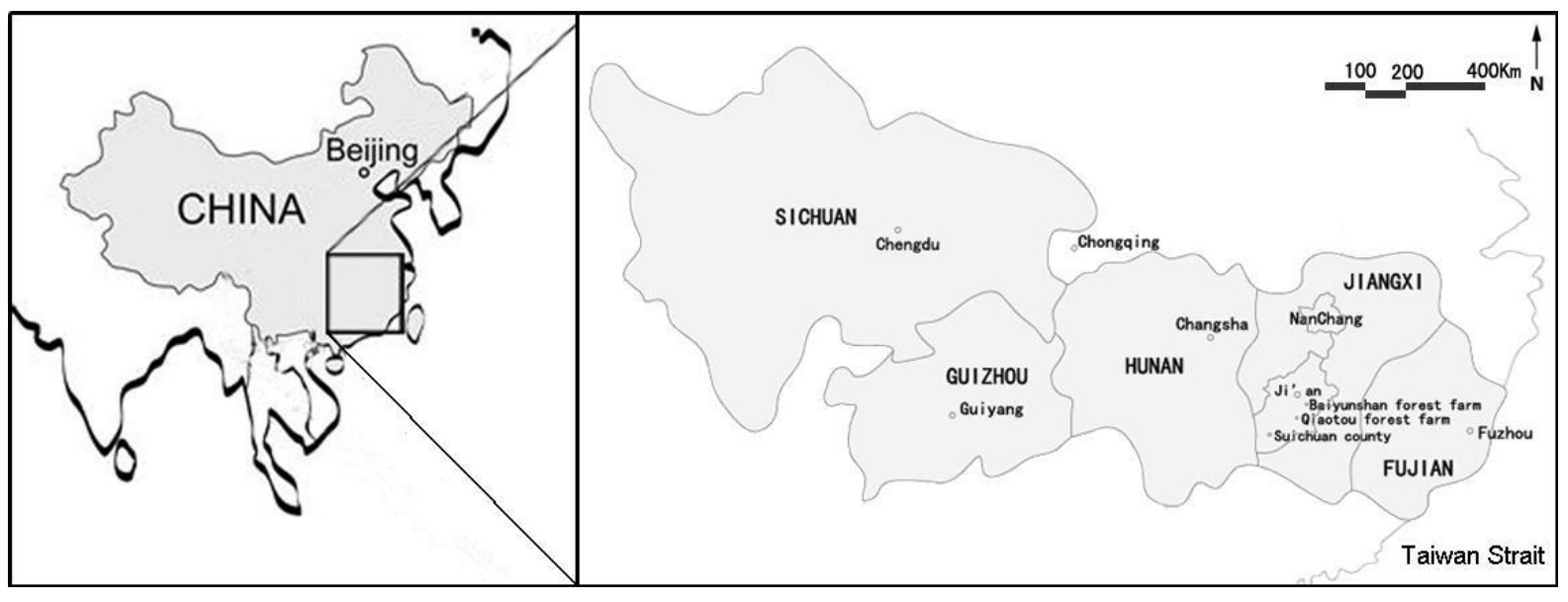

Figure 1. 


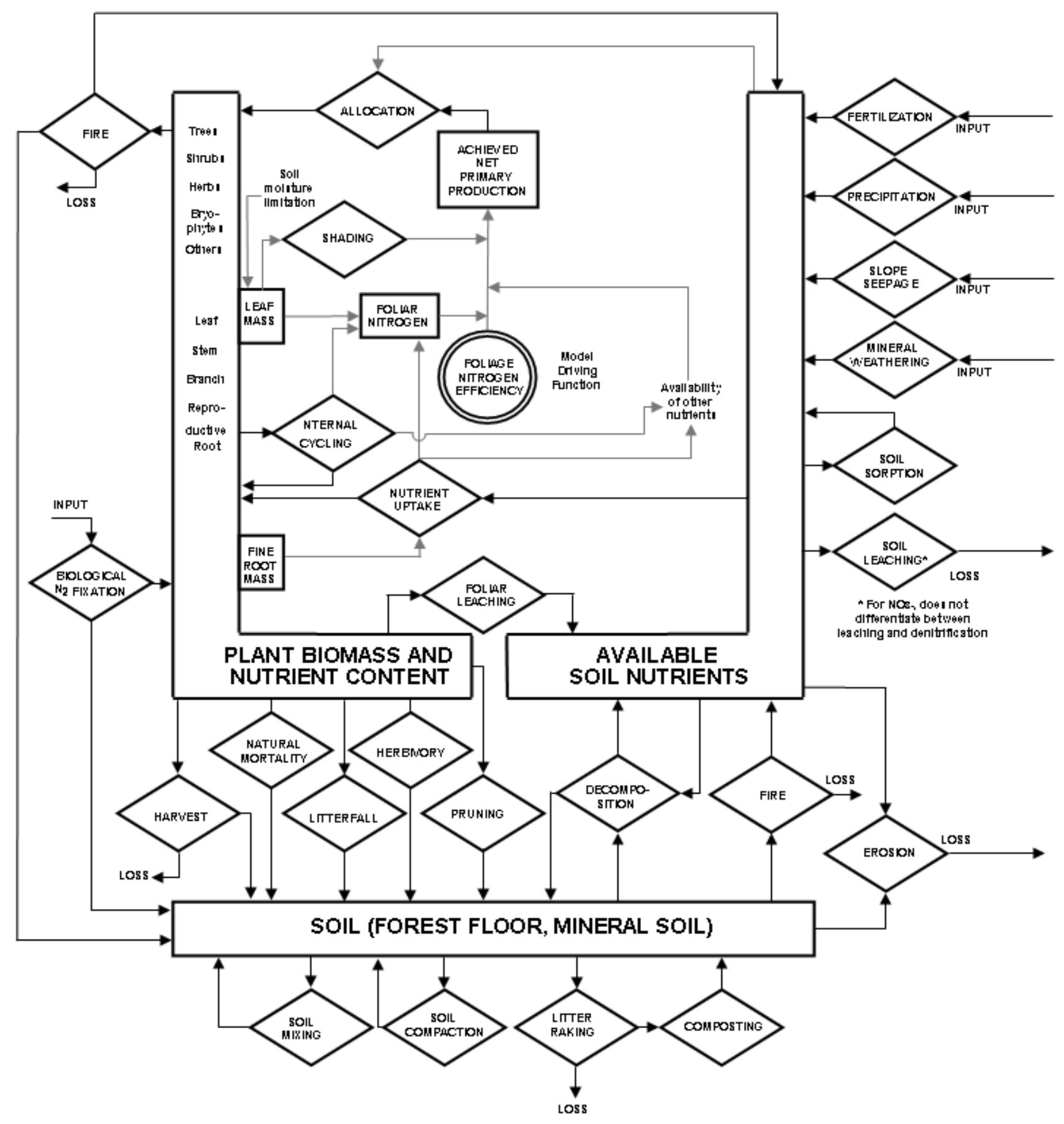

Figure 2. 

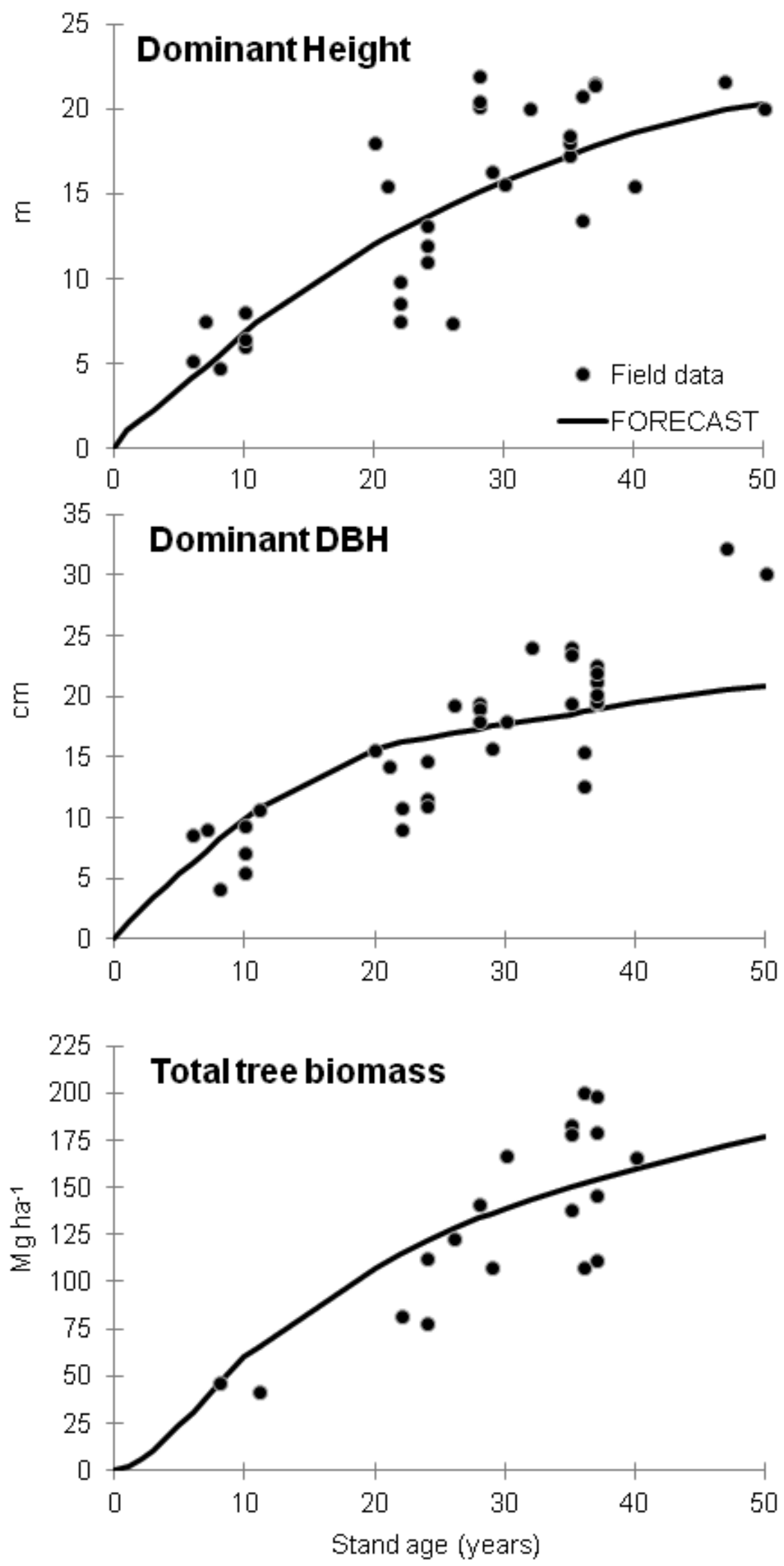

Figure 3 


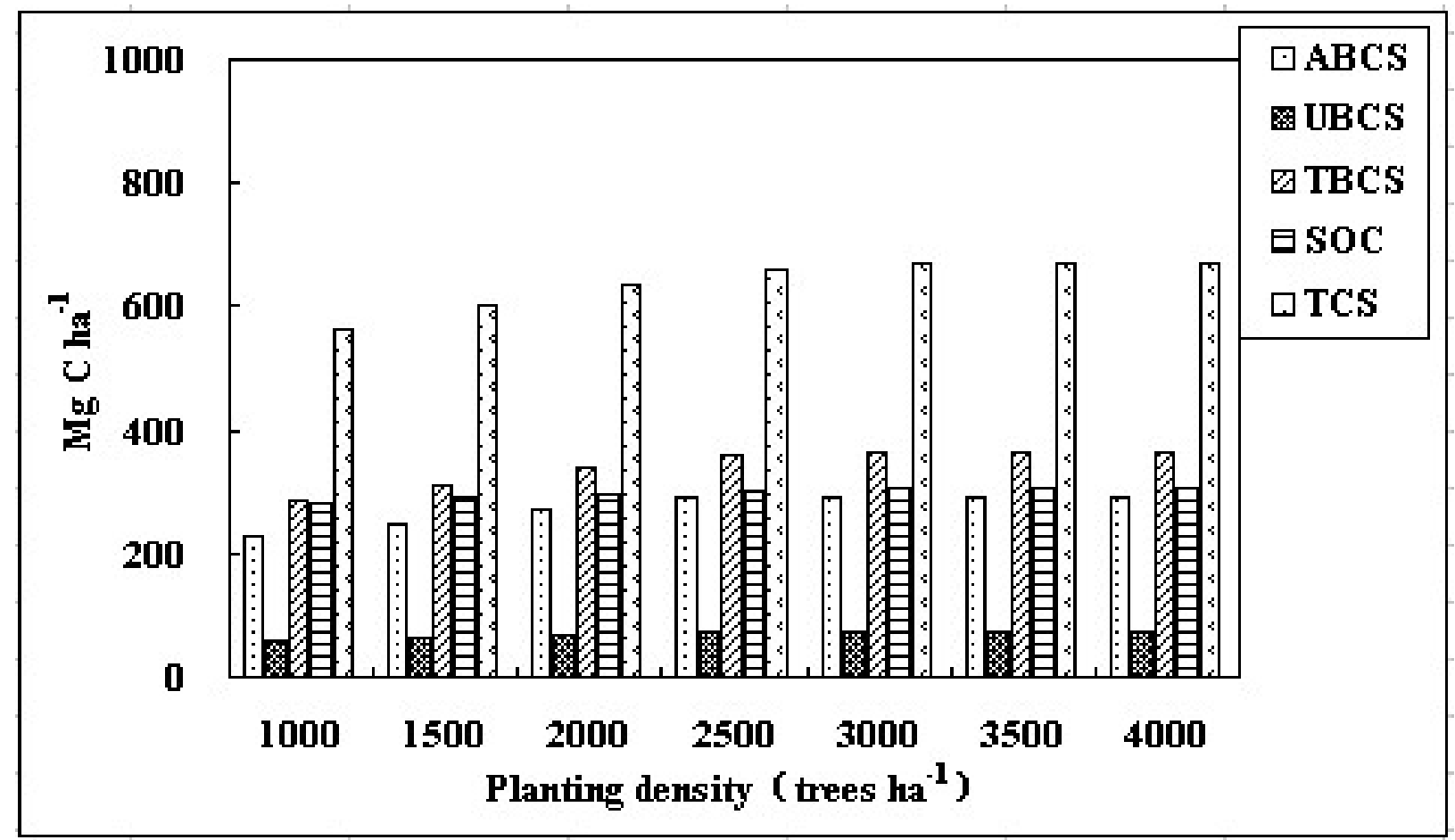

Figure 4 


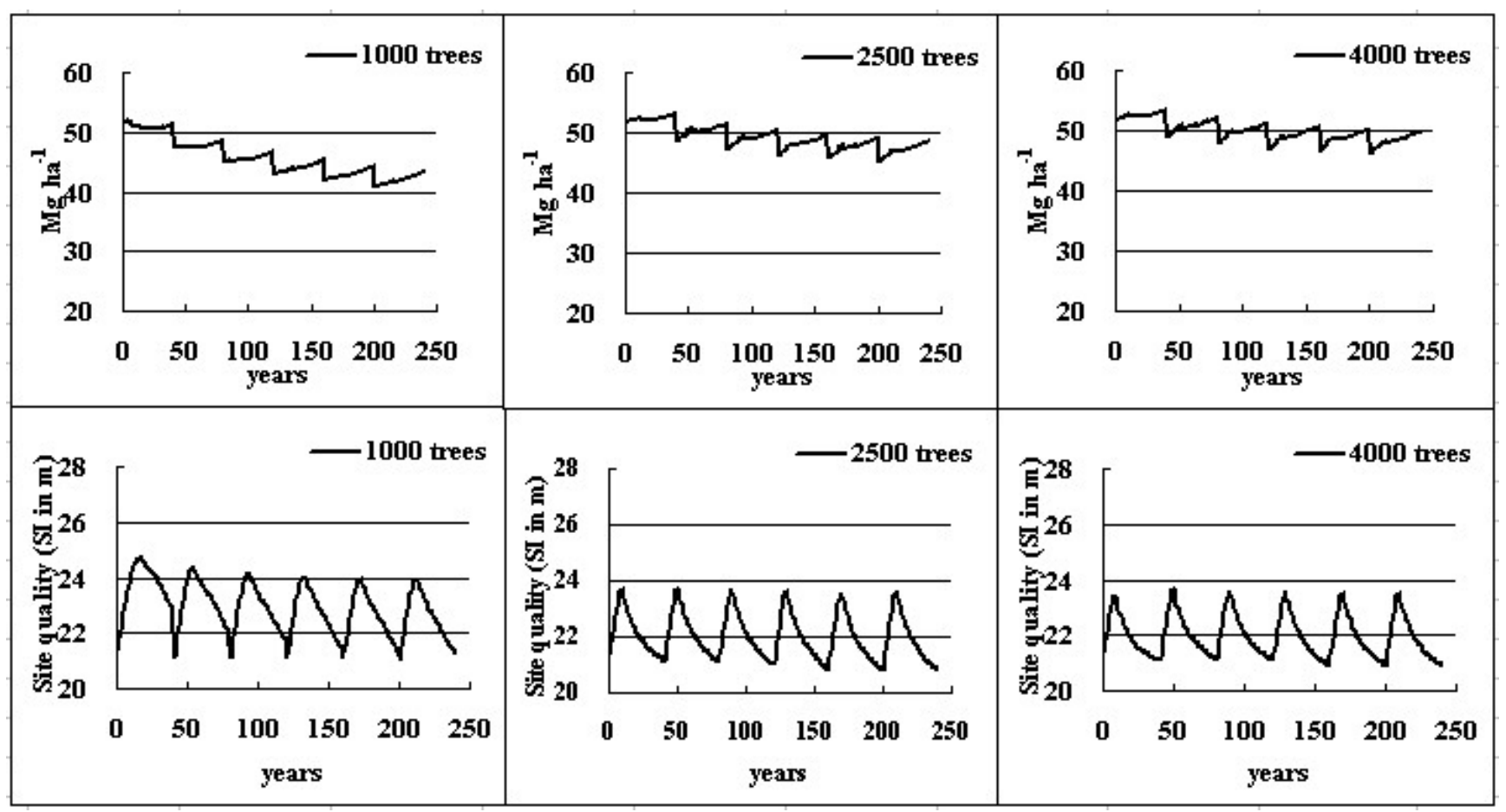

Figure 5 


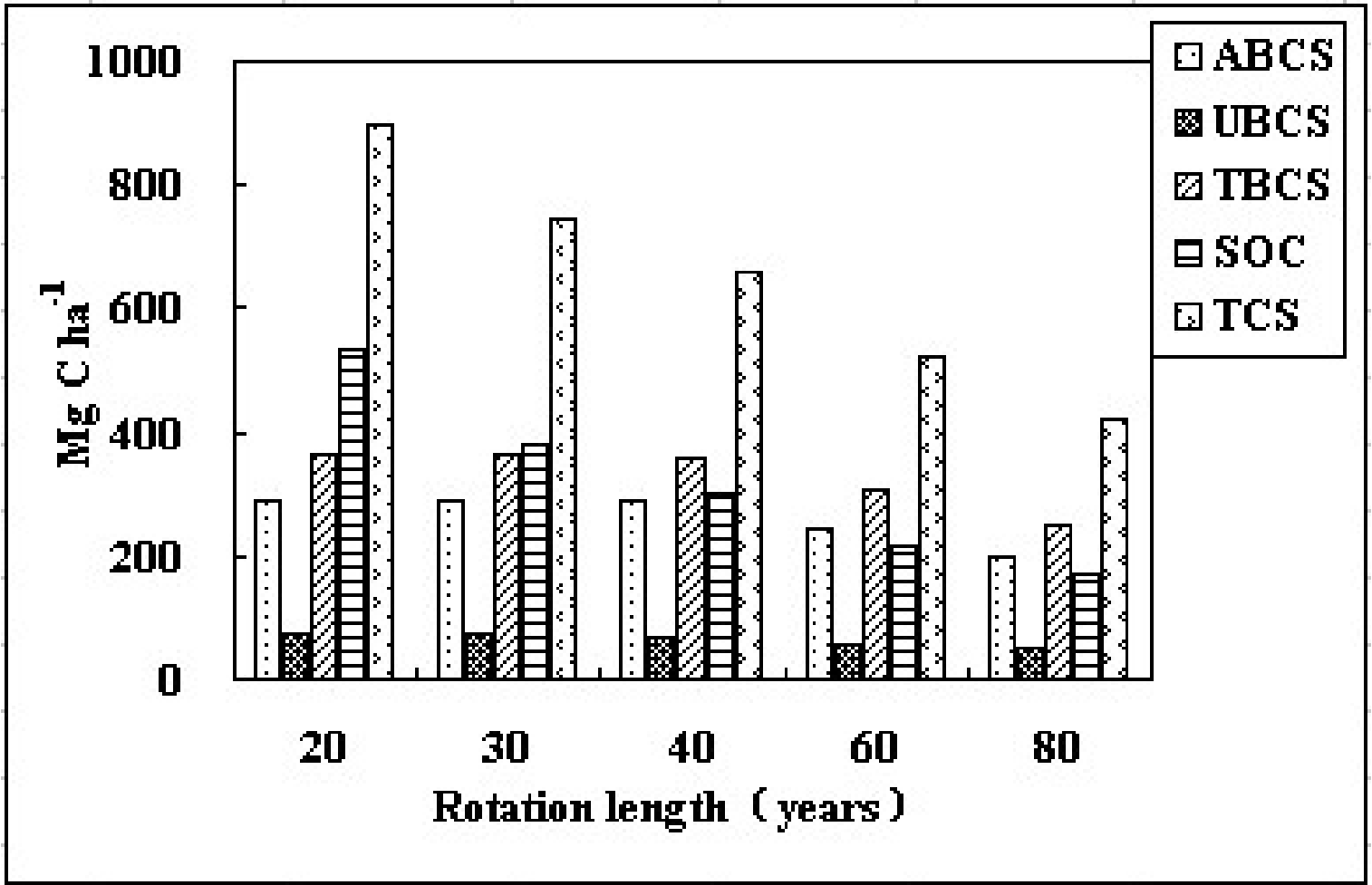

Figure 6 


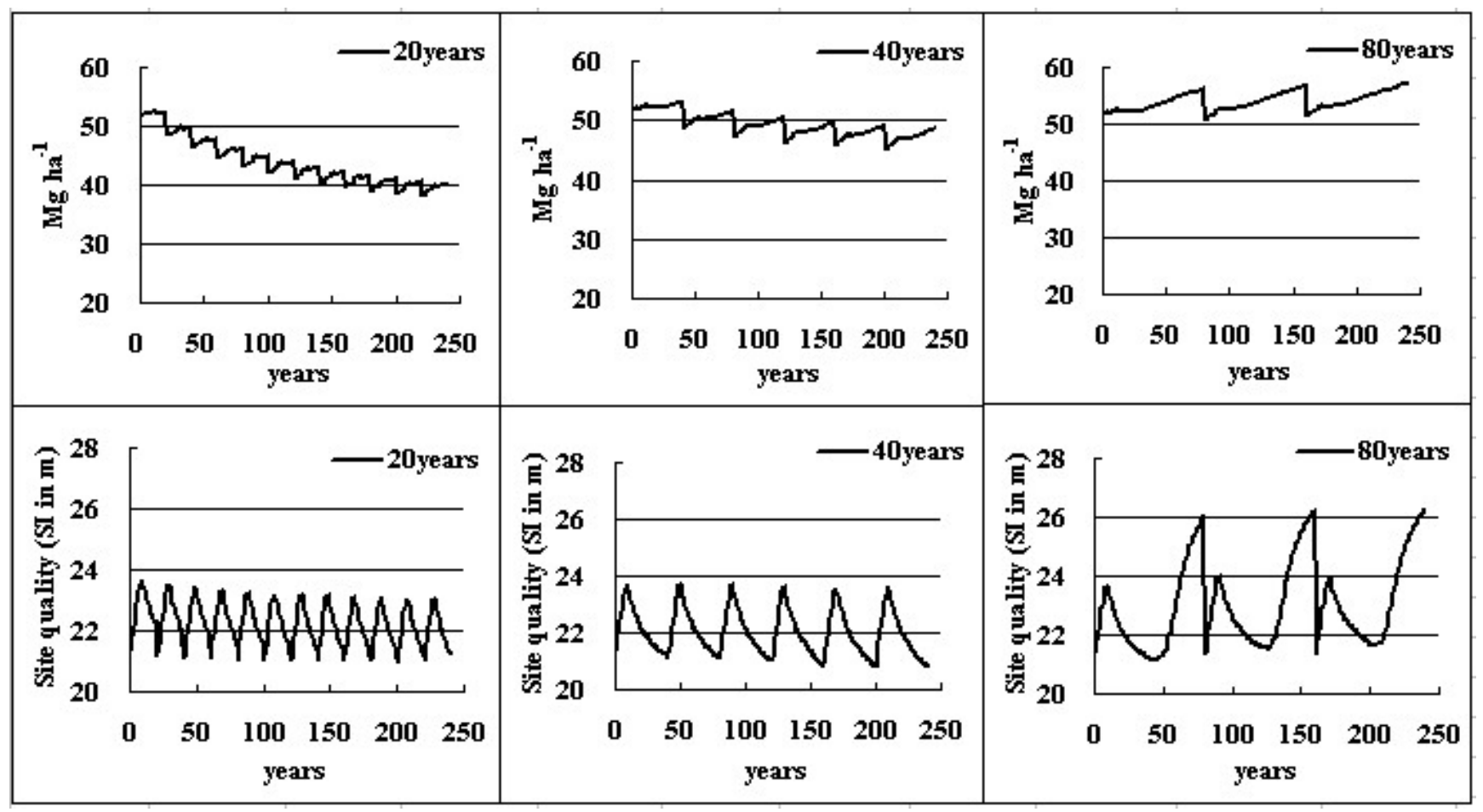

Figure 7 


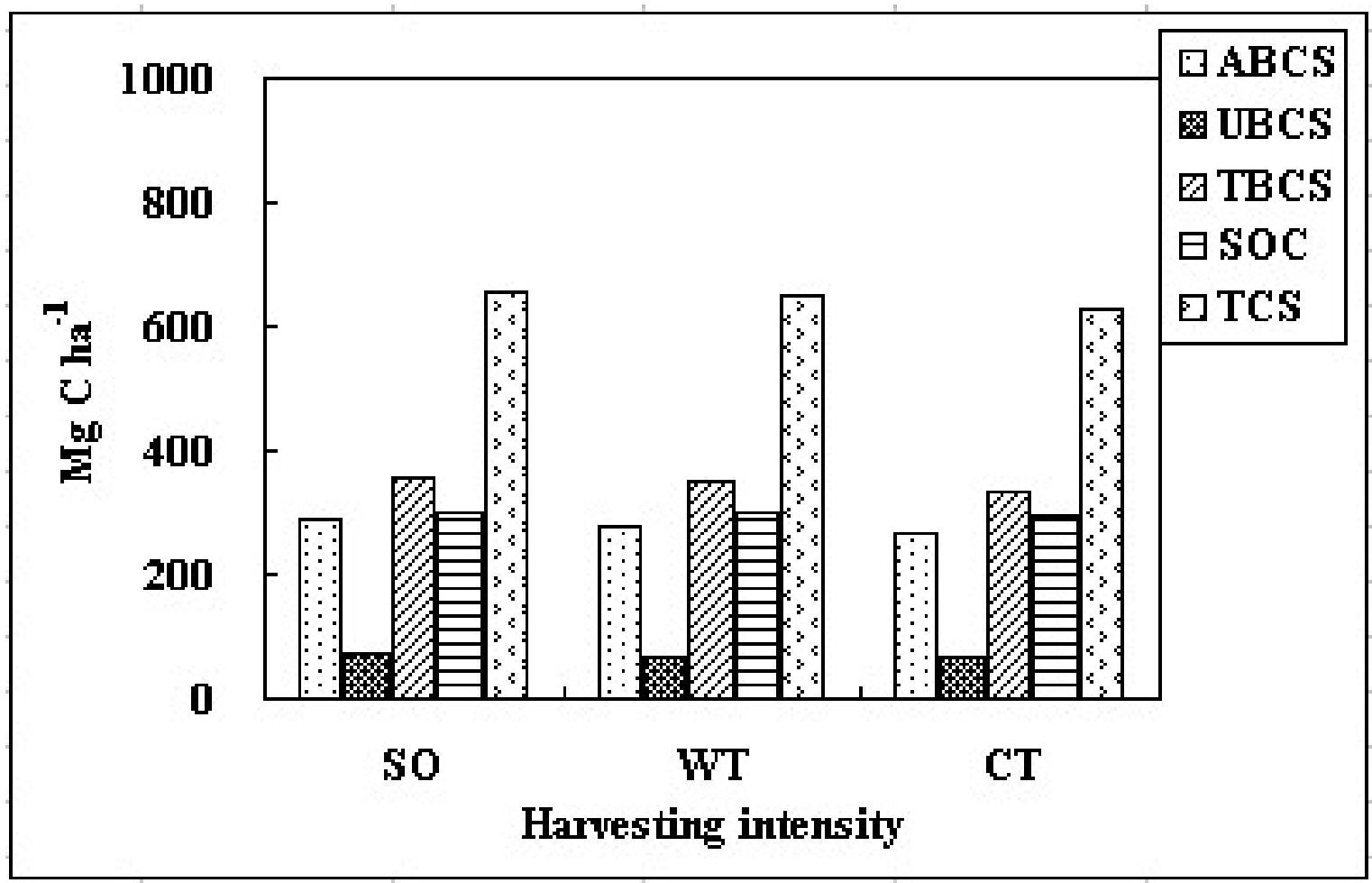

Figure 8 


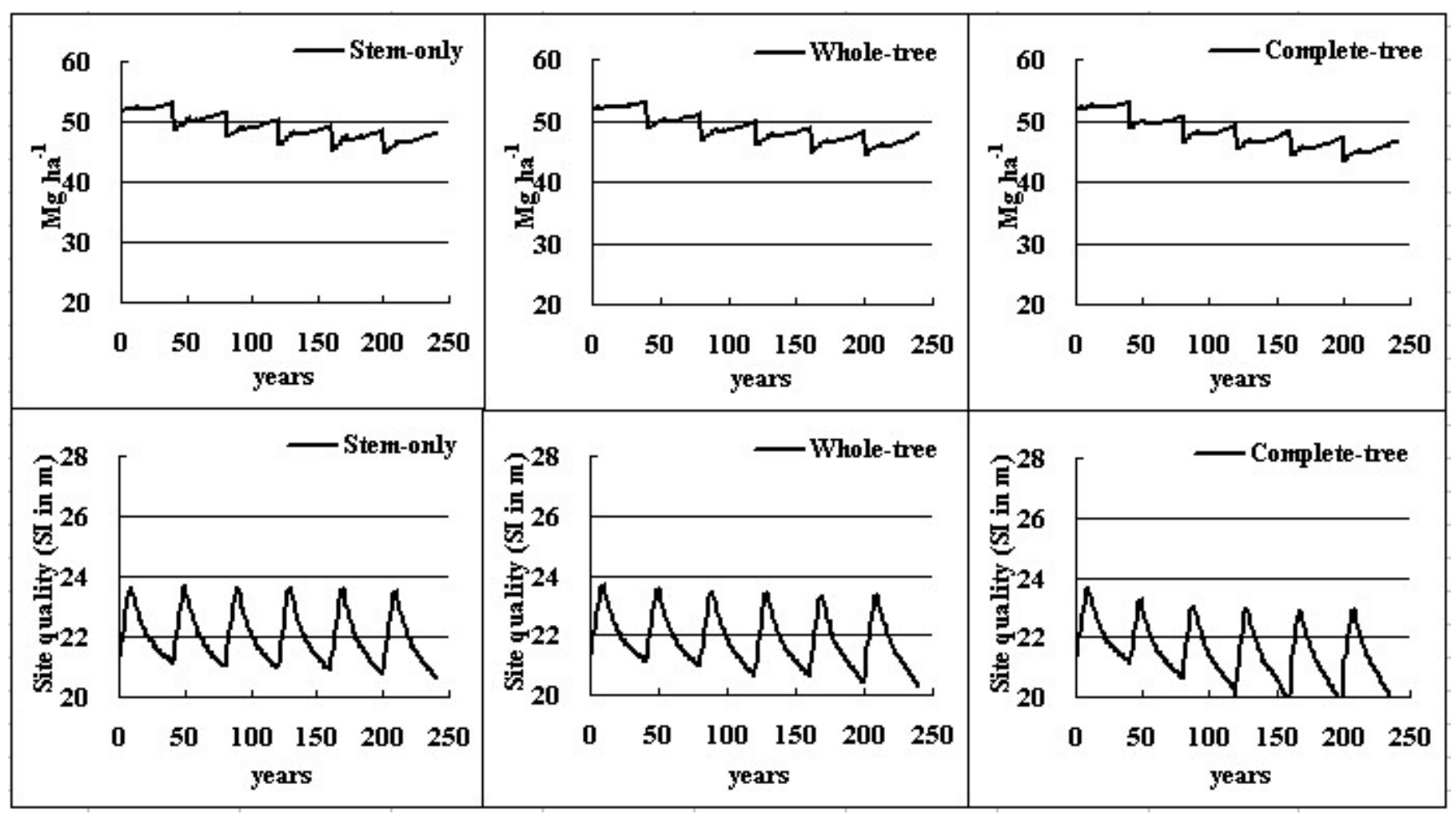

Figure 9 